\title{
Fast Regulation of Axonal Growth Cone Motility by Electrical Activity
}

\author{
Gaskon Ibarretxe, David Perrais, Frédéric Jaskolski, Alice Vimeney, and Christophe Mulle \\ Centre National de la Recherche Scientifique, Unité Mixte de Recherche 5091, Bordeaux Neuroscience Institute, Université Bordeaux 2, 33077 Bordeaux, \\ France
}

\begin{abstract}
Axonal growth cones are responsible for the correct guidance of developing axons and the establishment of functional neural networks. They are highly motile because of fast and continuous rearrangements of their actin-rich cytoskeleton. Here we have used live imaging of axonal growth cones of hippocampal neurons in culture and quantified their motility with a temporal resolution of $2 \mathrm{~s}$. Using novel methods of analysis of growth cone dynamics, we show that transient activation of kainate receptors by bath-applied kainate induced a fast and reversible growth cone stalling. This effect depends on electrical activity and can be mimicked by the transient discharge of action potentials elicited in the neuron by intracellular current injections at the somatic level through a patch pipette. Growth cone stalling induced by electrical stimulation is mediated by calcium entry from the extracellular medium as well as by calcium release from intracellular stores that define spatially restricted microdomains directly affecting cytoskeletal dynamics. We propose that growth cone motility is dynamically controlled by transient bursts of spontaneous electrical activity, which constitutes a prominent feature of developing neural networks in vivo.
\end{abstract}

Key words: growth cone; motility; development; kainate receptors; electrical activity; calcium microdomains

\section{Introduction}

Axonal growth cones are responsible for the correct growth of axons during nervous system development. They are guided by a large variety of extracellular local cues (Huber et al., 2003). In normal conditions, growth cones continuously change shape, extending and retracting filopodia and lamellipodia on a timescale of seconds (Gallo and Letourneau, 2004; Kalil and Dent, 2005). The sensitivity of growth cones to extracellular signals in their vicinity depends on this fast dynamic behavior (Zheng et al., 1996).

Among the known guidance cues, neurotransmitters have been shown to act over growth cones. Glutamate and acetylcholine act as chemoattractants for growth cones emitted by Xenopus laevis motoneurons (Zheng et al., 1994, 1996), and neurotransmitters such as acetylcholine or GABA are released by growth cones during stimulation (Young and Poo, 1983; Gao and van den Pol, 2000). Moreover, glutamate and GABA are released in the developing hippocampus and detected in neurons before they bear synapses (Demarque et al., 2002). Activation of glutamate ionotropic AMPA/kainate receptors affects axonal filopodial mo-

Received Sept. 16, 2006; revised May 29, 2007; accepted May 30, 2007.

This work was supported by the Centre National de la Recherche Scientifique, the Ministère de la Recherche of France, the Conseil Régional d'Aquitaine, and the European Commission [Synscaff program (for Synaptic Scaffolding Proteins Orchestrating Synapse Organisation during Development), Contract LSH-2003-511995]. G.I. was supported by a fellowship from the Basque Government. We thank Cécile Bats for her help with cultures of hippocampal neurons and Olivier Thoumine for critically reading this manuscript.

Correspondence should be addressed to Christophe Mulle, Laboratoire Physiologie Cellulaire de la Synapse, Centre National de la Recherche Scientifique, Unité Mixte de Recherche 5091, Bordeaux Neuroscience Institute, Université Bordeaux 2, 146 rue Léo Saignat, 33077 Bordeaux, France. E-mail: mulle@u-bordeaux2.fr.

D0I:10.1523/JNEUROSCI.1070-07.2007

Copyright $\odot 2007$ Society for Neuroscience $\quad$ 0270-6474/07/277684-12\$15.00/0 tility in culture (Chang and De Camilli, 2001; Schenk et al., 2003) and in hippocampal slices (Tashiro et al., 2003). Therefore, it was proposed that glutamate released locally, possibly in an autocrine manner, would affect growth cone motility and synaptogenesis (Tashiro et al., 2003). However, although the effect of neurotransmitter release may well affect growing axons locally, it could also act more classically on neuronal dendrites and regulate neuronal electrical activity.

Most of the emphasis on the regulation of growth cone behavior has been put on the study of local guidance cues. However, another intriguing and widespread feature of developing neural circuits is the coordinated spontaneous firing of large subsets of neurons during the perinatal period, coincident with synaptogenesis (O'Donovan, 1999; Ben-Ari, 2001). This activity is featured by episodes of high action potential frequency lasting from seconds to $\sim 1 \mathrm{~min}$, separated by periods of quiescence. Although electrical activity is essential for the correct formation of neural circuits (Goodman and Shatz, 1993; Zhang and Poo, 2001), the mechanisms whereby early spontaneous activity may influence axonal growth and the establishment of synapses have remained elusive. Sustained electrical stimulation for long periods $(>10$ min to days) inhibits axon elongation and eventually causes growth cone collapse (Cohan and Kater, 1986; Fields et al., 1990; Diefenbach et al., 2000). However, because electrical activity is intermittent in the developing brain and because neurotransmitters are expected to act on a short timescale before they are eliminated, it is important to assess whether transient excitations of neurons also affect growth cone behavior.

In this study, we show with high temporal resolution that transient activation of kainate receptors (KARs) induces a fast and reversible growth cone stalling, which comes along with an 
increase in shape irregularity. This effect depends on the ability of the cell to fire action potentials and can be mimicked by the sole electrical stimulation of spiking activity. Moreover, growth cone motility and stalling depend on intracellular calcium microdomains provided by extracellular and intracellular sources.

\section{Materials and Methods}

Hippocampal neuron cultures and transfection. Primary cultures of hippocampal neurons were obtained from neonatal pups of Swiss mice (Janvier, Le Genest-Saint-Isle, France) and glutamate receptor $G l u R 5^{-/-}$,

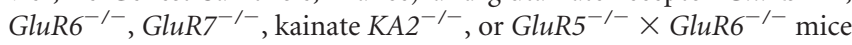
from a local animal facility as described previously (Jaskolski et al., 2004). Cultures were transfected at 6-7 d in vitro using Lipofectamine 2000 (Invitrogen, Carlsbad, CA) as described previously (Jaskolski et al., 2004), with actin-green fluorescent protein (GFP) (Fischer et al., 2000) or Discosoma Red (DsRed), or with a combination of GFP and myctagged GluR6 subunits (Jaskolski et al., 2004). Cells were used for experiments 1-4 d after transfection.

Growth cone imaging. Coverslips with cells were mounted into customized observation chambers perfused with HEPES-buffered saline solution (HBS) at $37^{\circ} \mathrm{C}$, controlled with an automatic temperature controller (TC-344B; Warner Instruments, Hamden, CT). HBS contained the following (in $\mathrm{mm}$ ): $145 \mathrm{NaCl}, 2 \mathrm{KCl}, 2 \mathrm{MgCl}_{2}, 2 \mathrm{CaCl}_{2}, 10$ glucose, and 10 HEPES, pH. 7.4 (320 mOsm). Transfected neurons were imaged on an Olympus (Tokyo, Japan) IX71 microscope with a $40 \times, 1$ numerical aperture oil objective (Olympus). The longest neurite of a given transfected neuron was taken as the axon, and one of its growth cones (if there is more than one axonal branch) was chosen for imaging. The axonal identity of the longest neurite was confirmed by the absence of mitogen-activated protein 2 (MAP2) immunostaining (antibody M4403; Sigma, St. Louis, MO). Images of growth cones were taken every $2 \mathrm{~s}$ with exposure times of $50-100 \mathrm{~ms}$ by a cooled 12-bit CCD camera (CoolSNAP ${ }_{\mathrm{HQ}}$; Roper Scientific, Tucson, AZ) driven by MetaMorph 6 (Universal Imaging, Downingtown, PA) for 5-15 min. Drugs were applied in the bath unless otherwise stated. All chemicals and drugs were from Sigma, except 6-cyano-7-nitroquinoxaline2,3-dione (CNQX), 2,3-dihydroxy-6-nitro-7-sulfonyl-benzo[f] quinoxaline (NBQX), GYKI53655 [1-(4-aminophenyl)-3-methylcarbamyl-4-methy17,8-methylenedioxy-3,4-dihydro-5H-2,3-benzodiazepine], tetrodotoxin (TTX), and thapsigargin (Tocris Bioscience, Ellisville, MO), ryanodine, Fluo-4-AM, Fluo-5F-AM, EGTA-AM, and BAPTA-AM (Invitrogen).

To image motility and intracellular calcium simultaneously, we used neurons transfected with DsRed. Coverslips were incubated for $15 \mathrm{~min}$ at $37^{\circ} \mathrm{C}, 5 \% \mathrm{CO}_{2}$ in equilibrated culture medium containing $2 \mu \mathrm{M}$ Fluo4-AM or Fluo-5F-AM. Simultaneous visualization of DsRed and Fluo-4 or Fluo-5F was obtained with Dual-View (Optical Insights, Tucson, AZ). High-speed $\mathrm{Ca}^{2+}$ imaging (see Fig. $7 E$ ) was performed with continuous illumination and an exposure time of $50 \mathrm{~ms}$.

Quantification of growth cone shape, dynamics, and extension. We quantified morphological parameters for each growth cone studied. Its size was determined by measuring the area $\mathrm{A}$ of a thresholded region corresponding to the cone. Its shape was estimated by an index that quantifies the degree of irregularity of the growth cone perimeter and thus the presence of filopodia. This shape index (SI) is defined by the formula $\mathrm{SI}=P^{2} / 4 \pi A$, where $P$ is the perimeter of the region corresponding to the cone (see Fig. 1C). SI is always $>1$ (value for a disc) and ranged from 1.8 (very regular growth cones) to 12 (irregular cones having many filopodia).

Growth cone motility was assessed by a motility index (MI) constructed as follows. The area covered by the growth cone during the recording period was determined by a threshold on the maximal image projection of the whole image stack over time. An equivalent area outside the growth cone was used for background. Pairs of consecutive frames were subtracted from each other with an added constant to avoid negative pixel values (see Fig. $1 A$ ). In these images, pixels with newly appearing structures are white, whereas disappearing structures are black. Highly motile structures will thus appear as highly contrasted on this type of image. This contrast is estimated by the SD of pixel values over the total area covered $\left(\mathrm{SD}_{\text {cone }}\right)$. MI is defined by the following formula:

$$
\mathrm{MI}=\frac{\left(\left(\mathrm{SD}_{\text {cone }}\right)^{2}-\left(\mathrm{SD}_{\text {background }}\right)^{2}\right)^{1 / 2}}{\mathrm{AI}_{\text {cone }}-\mathrm{AI}_{\text {background }}},
$$

where AI is the average intensity over the total growth cone (or background) area. The denominator corrects for different growth cone fluorescence intensities, reflecting different fluorescent protein expression levels, and for photobleaching.

Growth cone extension was measured by the displacement of growth cone centroid over time. The coordinates of the growth cone centroid were determined at different time points. For short-term ( $5 \mathrm{~min}$ ) experiments that evaluate the effect of kainate and electrical stimulations, point measurements of the centroid coordinates were made at $30 \mathrm{~s}$ intervals. For long-term (20-30 min) axonal outgrowth experiments, $2.5 \mathrm{~min}$ intervals were considered. The rate of centroid progression was calculated as the slope of the regression line of net displacement in the main direction of extension, with respect to the starting point, in control conditions and after treatment with kainate or electrical stimulation.

Electrophysiology. Neurons were recorded in cell-attached and wholecell configuration using a patch-clamp amplifier (EPC10; HEKA Elektronic, Lambrecht/Pfalz, Germany) driven by Pulse 8.6 software. Growth cones were imaged before seal formation with the patch pipette. After seal formation, the growth cone was recorded again, for at least $1 \mathrm{~min}$ in cell-attached mode, and in whole-cell mode for the rest of the experiment, when applicable. No difference in MI was observed neither before and after seal formation nor before and after breaking into whole cell. For cell-attached recordings, pipettes were filled with HBS. For whole-cell recordings, pipette solution contained the following (in $\mathrm{mM}$ ): 141 K-gluconate, $2 \mathrm{NaCl}, 2 \mathrm{MgCl}_{2}$, 0.5 EGTA, 10 HEPES, and $4 \mathrm{Na}_{2} \mathrm{ATP}, \mathrm{pH}$ $7.2(310 \mathrm{mOsm})$. Pipette resistance was 3-5 M . In current-clamp mode, membrane potential was kept at approximately $-60 \mathrm{mV}$ with less than $-400 \mathrm{pA}$ leak current. Basal growth cone motility was not affected by whole-cell recordings at $-60 \mathrm{mV}$ in the absence of stimulation. Action potentials were evoked by $10 \mathrm{~ms}$ square current injections that were adjusted in amplitude (200-800 pA) to evoke one action potential per current injection. Data analysis was made with Igor software (WaveMetrics, Lake Oswego, OR).

Immunocytochemistry. Surface live staining of myc-tagged kainate receptor subunits was accomplished as described previously (Jaskolski et al., 2004). GluR5 $5^{-1-} \times$ GluR6 $^{-1-}$ neurons were cotransfected with plasmids coding for myc-tagged GluR6 subunits and GFP. Images were acquired on a confocal microscope (Leica, Nussloch, Germany), run by the Bordeaux optical imaging facility (Plate-forme d'Imagerie Cellulaire, Institut des Neurosciences). Objects were defined by threshold and counted in 10 cells for each experimental condition in specified regions.

Statistical analysis. All experimental data averages are given as mean \pm SEM. Statistical differences between treatments were assessed by ANOVA and Student's $t$ test or alternatively by the nonparametric Kolmogorov-Smirnov (KS) test. KS test was also used to assess the normality of $\mathrm{MI}$ and $R$ value distributions in different experimental conditions. Correlation between measured parameters was calculated by the Pearson's linear determination coefficient $r^{2}$. These analyses were performed on Excel (Microsoft, Seattle, WA) and GraphPad Prism software (GraphPad Software, San Diego, CA).

\section{Results}

\section{Quantification of fast growth cone motility}

We developed a method to quantify axonal growth cone motility in primary cultures of hippocampal neurons. We transfected cells with plasmids coding for actin-GFP or DsRed and imaged fluorescent axonal growth cones. We confirmed the axonal identity of the longest neurite by immunostaining against MAP2, which is present in dendrites and excluded from the axon. At $6 \mathrm{~d}$ in vitro, the length of the longest MAP2 negative neurite was on average four times that of the longest MAP2-positive one in the same neuron (mean lengths, $595 \pm 75$ vs $141 \pm 32 \mu \mathrm{m}$, respectively; 

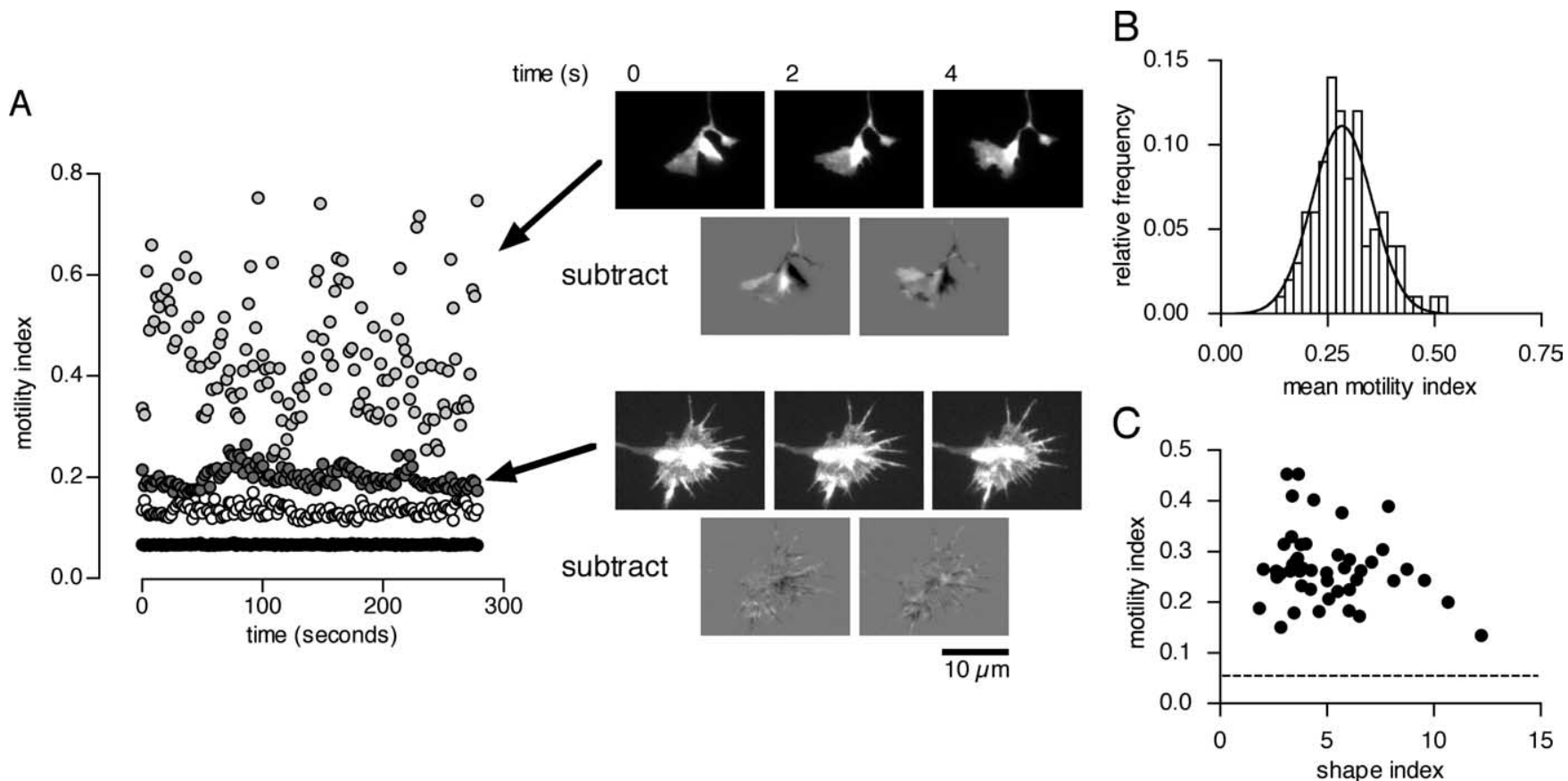

Figure 1. Quantification of fast growth cone motility. A, Left, Ml over time for four growth cones showing the observed range of behaviors. Ml is calculated every $2 \mathrm{~s}$. The bottom trace corresponds to a growth cone fixed with paraformaldehyde. See also supplemental movie 1 (available at www.jneurosci.org as supplemental material). Right, Three consecutive images of two of the growth cones represented, indicated by arrows. For each pair of consecutive images, a subtract image is created (see Materials and Methods). Note that the very motile growth cone presents a greater range of pixel values (stronger bright and dark areas) in the subtract image than the other, less motile growth cone. $\boldsymbol{B}$, The distribution of mean basal motility index values follows a Gaussian-like distribution (actin-GFP; $n=100$ ). C, Chart showing that MI is independent of growth cone morphology, as estimated by the shape index (actin-GFP; $n=49$ ). Dashed line represents MI measured for fixed growth cones.

$n=7)$. To characterize growth cone motility quantitatively and to explore factors controlling this behavior on a fast timescale, we defined an instantaneous MI of the whole growth cone area (see Materials and Methods) (Fig. $1 A$ ). This dimensionless numerical index reflects the global motility behavior of growth cones, regardless of their particular changes in shape, such as filopodia extension or retraction, or lamellipodia changes. For a given growth cone, the mean MI value remained stable for minutes, ranging from $\sim 0.1$ (very low motility) to 0.5 (very high motility). On average, the actin-GFP- or DsRed-labeled growth cones had very similar MIs $(0.29 \pm 0.01, n=100$ for actin-GFP and $0.27 \pm$ $0.01, n=99$ for DsRed, respectively). KS test for normality indicated that the distribution of MI values in both samples was consistent with a Gaussian distribution (Fig. $1 B$ ). Growth cones rendered immobile with paraformaldehyde fixation displayed a MI value of $0.07 \pm 0.01$ (actin-GFP; $n=5$ ), setting a lower limit on MI values in our system. MI was not dependent on growth cone fluorescence, which reflects actin-GFP or DsRed expression levels (Pearson's $r^{2}=0.1$ ), and it was stable over minutes of observation (103 $\pm 4 \%$ of initial MI after $5 \min ; n=9)$, despite significant photobleaching ( $88 \pm 2 \%$ of initial fluorescence). Finally, MI was not dependent on growth cone size, ranging from 12 to $125 \mu \mathrm{m}^{2}$ (Pearson's $r^{2}=0.02$ ), or on its particular shape, as estimated by the shape index (see Materials and Methods; Pearson's $r^{2}=0.002$ ) (Fig. 1C). In conclusion, the instantaneous motility index MI provides a reliable and resolutive method to measure the fast dynamics of growth cones.

\section{Kainate receptor activation reversibly stalls axonal growth cones}

We next analyzed the effects of kainate receptor activation on growth cone motility. Previous work has shown that the sus- tained activation of ionotropic glutamate AMPA/kainate receptors by exogenous agonists induced a blockade of the motility of axonal filopodia, in hippocampal neuronal cultures (Chang and De Camilli, 2001) as well as in hippocampal slices in culture (Tashiro et al., 2003). In our recording conditions, kainate (20 $\mu \mathrm{M})$ applied to the bath for $40 \mathrm{~s}$ induced a fast and prominent growth cone stalling that was reversible within minutes of agonist washout (Fig. $2 A, B$ ). After complete washout, subsequent applications of kainate induced a similar stalling.

We tested the effect of kainate on MI in a population of cultured hippocampal neurons. The response of each growth cone was quantified by the ratio $R=\mathrm{MI}_{1} / \mathrm{MI}_{0}$, where $\mathrm{MI}_{0}$ represents the average MI before kainate application and $\mathrm{MI}_{1}$ the average motility index during kainate action. KS test for normality indicated that the distribution of $R$ values in every experimental condition was consistent with a Gaussian distribution. Kainate applications diminished $R$ values (mean $R=0.85 \pm 0.03 ; n=54$ ) compared with control saline applications (mean $R=0.99 \pm$ $0.01 ; n=80 ; p=0.001$, KS test) (Fig. $2 C$ ). Nevertheless, only $\sim 25 \%$ of the growth cones tested with kainate decreased their motility below the lowest level attained under similar conditions with saline solution $(R=0.79)$. Thus, significant heterogeneity exists within the cultured hippocampal neuron population with respect to the sensitivity of growth cones to kainate.

We tested different kainate concentrations and found that a maximal effect was induced by $20 \mu \mathrm{m}$ kainate. Lower doses did not induce a significant change of growth cone motility (Fig. 2D), unlike what was observed for axonal filopodia in hippocampal slices (Tashiro et al., 2003). However, long-term applications of $0.5 \mu \mathrm{M}$ kainate for $20 \mathrm{~min}$ induced a decrease in the rate of axonal outgrowth, from $0.45 \pm 0.05 \mu \mathrm{m} / \mathrm{min}$ (control conditions) to $0.22 \pm 0.06 \mu \mathrm{m} / \mathrm{min}$ in the presence of $0.5 \mu \mathrm{M}$ kainate $(n=7 ; p=$ 
A
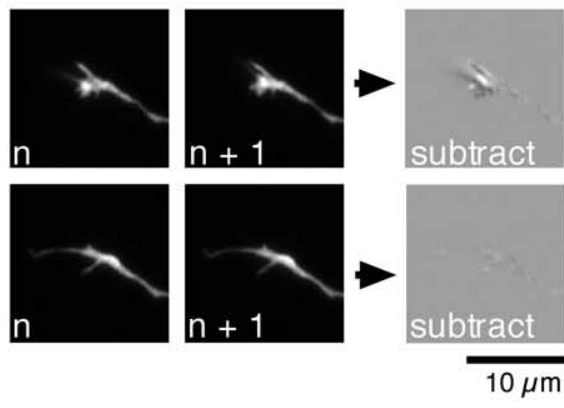

D

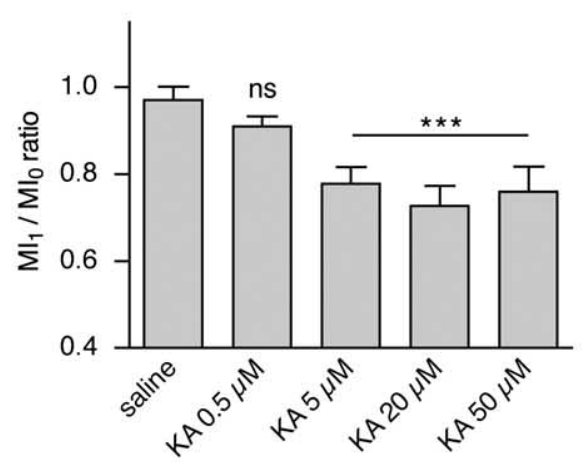

B

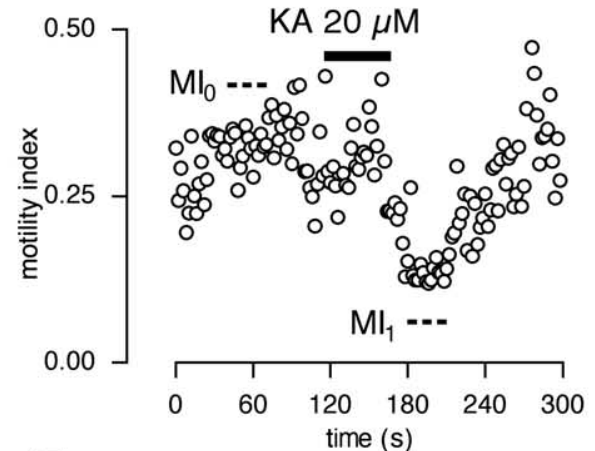

E

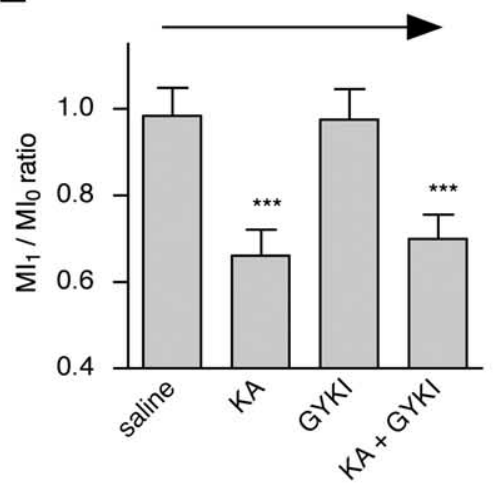

C

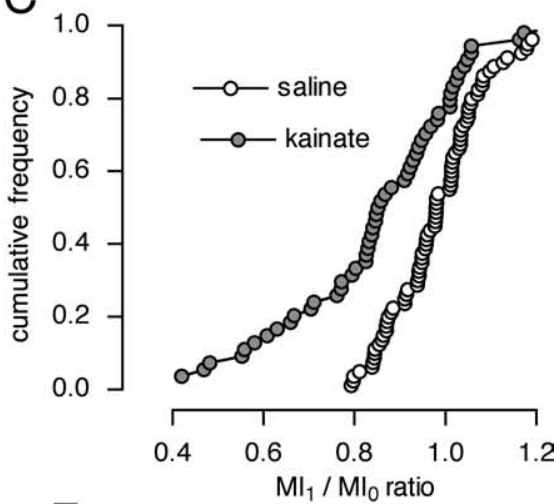

$\mathrm{F}$

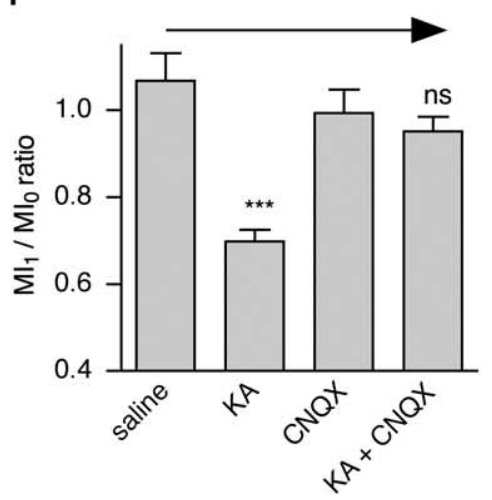

Figure 2. Kainate reversibly stalls axonal growth cones. $A$, Effect of bath-applied $20 \mu \mathrm{m}$ kainate to neuronal cultures. Note that the pixel values in the subtract image become more homogeneous over the growth cone area during kainate application. Note also increased filopodia extension after kainate (shape index in the example raised by $80 \%$ ). See supplemental movie 2 (available at www.jneurosci.org as supplemental material). $\boldsymbol{B}$, Kinetics of the effect of kainate application on a growth cone $\mathrm{Ml}$. $\boldsymbol{C}$, Cumulative frequency distribution of $R=\mathrm{MI}_{1} / \mathrm{MI}_{0}$ ratios in populations of growth cones expressing actin-GFP and exposed to saline solution ( $n=80$; white circles) or $20 \mu \mathrm{m}$ kainate for $40 \mathrm{~s}$ ( $n=54$; gray circles). Approximately $25 \%$ of the kainate-exposed growth cones present $R<0.79$ (threshold for stalling, minimal value in the saline trace). $\boldsymbol{D}$, Effect of varying kainate concentration. Kainate at micromolar concentrations stalls growth cones, whereas submicromolar concentrations do not affect MI $(n=7)$. $\boldsymbol{E}, \boldsymbol{F}$, Effect of GYKI53655 (E; $100 \mu \mathrm{M})$ and CNQX ( $\boldsymbol{F} ; 50 \mu \mathrm{m})$ on kainate induced MI decrease on growth cones. Cones in which a clear effect of kainate was observed $(R<0.79)$ were incubated with the antagonist for $10 \mathrm{~min}$. Kainate was then applied for a second time with the antagonist. The response is unaffected by GYKI 53655 ( $n=$ 4), whereas it is completely blocked by CNQX $(n=4)$. Arrows indicate the order of different drug applications. ${ }^{* * *} p<0.001$, Tukey's test, ANOVA.

0.02, Student's test) (supplemental Fig. 1A, available at www. jneurosci.org as supplemental material). Thus, chronic longterm stimulations with kainate, even at low concentrations that do not induce stalling, can nevertheless affect axonal outgrowth.

Kainate at micromolar concentrations can activate both AMPA and kainate receptors. The effect of kainate on MI was not affected by the presence of $100 \mu \mathrm{M}$ GYKI53655 (Fig. 2 E), a selective AMPA receptor antagonist (Lerma, 2003), although it was blocked by $50 \mu \mathrm{M}$ CNQX, an antagonist of AMPA and kainate receptors (Fig. $2 F$ ). This pharmacological profile showed that growth cone stalling induced by $20 \mu \mathrm{M}$ kainate is selectively mediated by kainate receptors. Growth cone stalling induced by 20 $\mu \mathrm{M}$ kainate was also associated with a $32 \pm 1 \%$ increase in the shape index $(n=12)$. Moreover, the block of rapid motility was also paralleled with an abrupt halt in the displacement of the growth cone centroid. The average rate of centroid progression $(n=12)$ in control conditions was $0.87 \pm 0.14 \mu \mathrm{m} / \mathrm{min}$, which decreased to $0.16 \pm 0.3 \mu \mathrm{m} / \mathrm{min}$ in the next $2 \mathrm{~min}$ after exposure to $20 \mu \mathrm{M}$ kainate.

The stalling effect of kainate is mediated by GluR6-containing kainate receptors

Native kainate receptors are formed by the heterologous assembly of the different subunits GluR5, GluR6, GluR7, KA1, and KA2. Among these, GluR5, GluR6, and GluR7 can form functional homomeric receptor channels, and the presence of at least one pore-forming subunit is necessary for the kainate receptor complex to assemble (Jaskolski et al., 2005). To determine which kainate receptor subunits were necessary for growth cone stalling, we evaluated the effect of kainate applications on neurons cultured from knock-out mice for different kainate receptor subunits. The growth cone stalling response induced by $20 \mu \mathrm{M}$ kainate was preserved in $G l u R 5^{-/-}, G l u R 7^{-/-}$, and $K A 2^{-/-}$neurons (data not shown). However, we found that the stalling response was completely abolished in growth cones from $\mathrm{GluR6}^{-/-}$neurons (mean $R=1.02 \pm 0.03 ; n=20$ ) (Fig. $3 A$ ), as well as in GluR5 $5^{-1-} \times$ GluR6 $^{-/-}$neurons (mean $R=0.97 \pm 0.02 ; n=26$ ) (Fig. $3 B$ ). In both cases, the cumulative distribution plot of $R$ values matched that of saline applications, and no growth cones presented $R$ values below 0.79 . Therefore, the expression of the KAR subunit GluR6 is necessary for kainate to induce axonal growth cone stalling.

This latter result is consistent with the fact that neurons from GluR5 $5^{-1-} \times$ GluR6 $^{-1-}$ mice are devoid of functional kainate receptors at 7-10 din vitro (Coussen et al., 2005). To confirm that GluR6 was indeed responsible for the stalling effects of kainate, we restored its expression by transfecting recombinant GluR6 subunits. The recombinant GluR6 subunits were tagged with GFP (Coussen et al., 2005) to identify and select transfected neurons for the motility assay performed by imaging cotransfected DsRed fluorescence. Interestingly, we found that, when GluR5 ${ }^{-1-} \times \mathrm{GluR6}^{-1-}$ neurons were transfected with both 
GluR6 subunit splice variants GluR6a and GluR6b, the stalling response to kainate was restored to similar rates to that of wild-type neurons (mean $R=0.85 \pm 0.04$; $n=20 ; p<0.05$, with respect to nontransfected cells, KS test) (Fig. 3B), but nevertheless, there were many GluR6-GFPtransfected neurons whose growth cones did not stall $(R>0.79$ in 14 of 20 cells). This suggests that the lack of effect of kainate in a majority of neurons is not attributable to the lack of kainate receptors. In addition, the complete rescue of the stall-

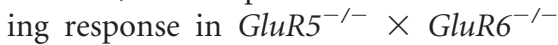
neurons only took place when both recombinant subunits were cotransfected. Neither GluR6a (mean $R=0.95 \pm 0.04$; $n=20$ ) nor GluR6b (mean $R=0.92 \pm$ $0.02 ; n=20$ ) induced a significant recovery of the effect when transfected alone ( $p>0.05, \mathrm{KS}$ test), all cones presenting $R$ values $>0.79$. Thus, the stalling effect of kainate depends on the presence of heteromeric GluR6a- and GluR6b-containing kainate receptors.

We next wanted to determine the cellular localization of the kainate receptors responsible for the stalling effect on growth cones. Many guidance signals for axonal growth cones have a local action, and the receptors for these guidance molecules have been described to be surface expressed at the growth cone itself (Huber et al., 2003). Because no extracellular epitope KAR antibody is yet usable for immunocytochemistry, we transfected GluR5 $5^{-/-} \times$ GluR6 $^{-/-}$hippocampal neurons with myc-tagged GluR6a or GluR6b and quantified their relative surface expression by confocal microscopy (Fig. 3C). For both splice variants, the number of receptor clusters per unit area was much lower (approximately one-fifth) at the axonal growth cone than at the somatodendritic compartment (Fig. 3D). Thus, in conditions in which axonal growth cone stalling can be rescued, the majority of kainate receptors have a somatodendritic membrane location.

\section{Electrical activity causes fast growth cone stalling}

The results of surface immunostaining experiments suggested a role for somatodendritic kainate receptors in axonal growth cone stalling. Action potentials generated by the somatodendritic depolarization induced by KAR activation could propagate to the distant axonal growth cone. Therefore, we examined whether the action of kainate required the generation of action potentials by testing the effect of TTX. In a sample of four growth cones clearly responding to $20 \mu \mathrm{M}$ kainate (mean $R=0.59 \pm 0.07$ ), the stalling effect was blocked by $1 \mu \mathrm{M}$ TTX, and it could be reversed after 15 min of TTX washout (Fig. 4A). TTX had the same effect in GluR5 $5^{-1-} \times$ GluR6 $^{-1-}$ neurons transfected with GluR6b and GluR6a (data not shown). This result was consistent with an involvement of somatodendritic KARs that activate voltage$(n=10)$.
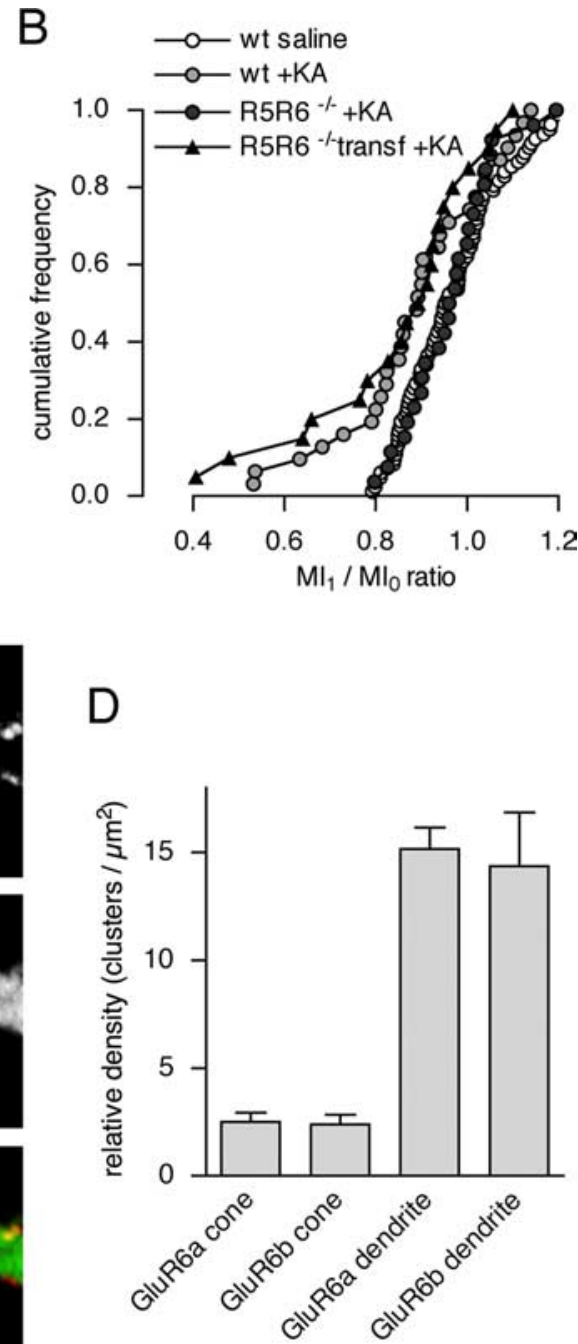

Figure 3. Involvement of GluR6-containing kainate receptors in growth cone stalling. $\boldsymbol{A}, \boldsymbol{B}$, The effect of kainate $(20 \mu \mathrm{m} ; 40 \mathrm{~s})$ ( with DsRed, is not different from the effect of saline solution (white circles). The effect of kainate is rescued in GluR5 $5^{-/-} \times$ neurons by transfection with plasmids coding for GluR6a and GluR6b recombinant subunits, in addition to DsRed ( $\boldsymbol{B}_{i}$ the whole neuron, myc-R6a and untagged R6b. Scale bar, $2 \mu \mathrm{m}$. D, Quantification of surface myc-GluR6a and myc-GluR6b expression by confocal microscopy, in mean \pm SEM number of immunoreactive clusters per square micrometer

dependent $\mathrm{Na}^{+}$channels for kainate-mediated growth cone stalling.

To directly evaluate the role of electrical activity in this effect, we recorded action potentials of neurons exposed to kainate with patch clamp in cell-attached configuration, together with timelapse imaging of axonal growth cone motility in the same cell (Fig. $4 B$ ). In some neurons, kainate applications did not induce the firing of action potentials. In these silent neurons, kainate did not affect growth cone motility (mean $R=0.99 \pm 0.03 ; n=12$ ). However, in a large proportion of neurons (17 of 29), action potentials were quickly generated after the start of the kainate perfusion, reaching an average frequency of $7 \pm 2 \mathrm{~Hz}$, measured over $30 \mathrm{~s}$ after kainate applications (Fig. 4B). Some of these growth cones presented clear stalling responses. Those with the clearest responses $(R<0.79)$ were associated with a firing frequency of $10 \pm 4 \mathrm{~Hz}(n=9)$. Overall, there was a moderate 


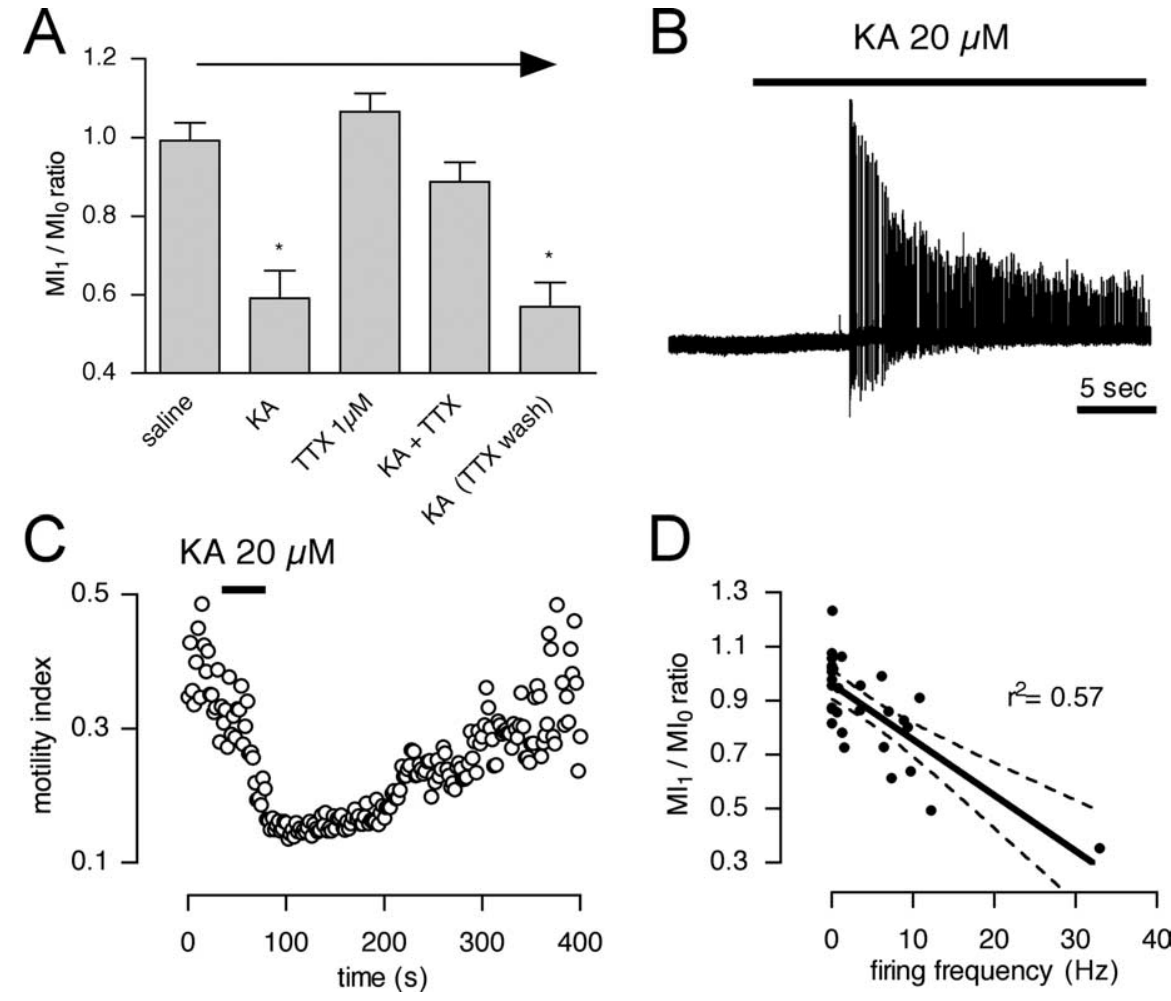

Figure 4. Neurons fire action potentials during growth cone stalling. $\boldsymbol{A}$, The stalling effect of $20 \mu \mathrm{m}$ kainate, $40 \mathrm{~s}$ is blocked by preincubation with $1 \mu \mathrm{m}$ TTX for $10 \mathrm{~min}$. Arrow indicates the order of drug applications. Data are expressed as mean \pm SEM for growth cones $(n=4)$ clearly responding to kainate $(R<0.79) .{ }^{* * *} p<0.001$, Tukey's test, ANOVA. B, Somatic cell-attached recording of a neuron during kainate application. Shortly after the onset of application, the neuron fired action potentials at an average frequency of $12 \mathrm{~Hz}$. $\boldsymbol{C}$, The growth cone of the neuron illustrated in $\boldsymbol{B}$ reversibly decreased MI. $\boldsymbol{D}$, The effect of kainate on growth cone motility shows a moderate degree of correlation with mean firing frequency (Pearson's $r^{2}=0.57 ; n=29$ ). Dotted line represents $95 \%$ confidence interval for the decrease in motility at a given action potential frequency.

time-lapse imaging of growth cone motility (Fig. 5A). When neurons were induced to fire action potentials at $10 \mathrm{~Hz}$ for $40 \mathrm{~s}$, a firing rate reached by many neurons stimulated by kainate, this provoked a clear growth cone stalling response (mean $R=$ $0.81 \pm 0.03 ; n=38$; KS test, $p<0.001)$ (Fig. 5A,B) (supplemental movie 3, available at www.jneurosci.org as supplemental material). Nevertheless, there was still a significant proportion of growth cones $(\sim 40 \%)$ that did not stall $(R>0.79)$ in response to the electrical stimulation. The stalling effect displayed a fast temporal profile qualitatively similar to that mediated by kainate. Interestingly, although action potentials propagate to axonal growth cones within milliseconds, the MI decreased progressively after the onset of the stimulation and reached a minimal value when the stimulation ceased. Thereafter, motility slowly recovered reaching control values in $\sim 2 \mathrm{~min}$ (Fig. $5 B$ ). Electrical stimulation at $10 \mathrm{~Hz}$ for $40 \mathrm{~s}$ also increased the shape index by $29 \pm 0.03 \%(n=12)$ (Fig. $5 D$ ), an effect similar to the one observed with kainate applications. Moreover, stimulation also caused a transient retraction of the growth cone, as reflected in the measurement of centroid progression (Fig. $5 E)$. The rate of centroid displacement changed from $0.58 \pm 0.21 \mu \mathrm{m} / \mathrm{min}$ (measured $2 \mathrm{~min}$ before; control conditions) to $-0.74 \pm 0.35 \mu \mathrm{m} / \mathrm{min}$ in the next $2 \mathrm{~min}$ after the onset of stimulation $(n=12)$.

degree of correlation between the firing frequency induced by kainate and the growth cone motility response $R$ (Pearson's $r^{2}=$ 0.57) (Fig. 4D). Together, these findings strongly suggest that the stalling effect of kainate is sequentially mediated by the activation of somatodendritic kainate receptors, activation of voltage-gated $\mathrm{Na}^{+}$channels, and discharge of action potentials that would eventually propagate and reach the axonal growth cone. We also evaluated whether the decrease of axonal outgrowth rate by low concentrations of kainate $(0.5 \mu \mathrm{M})$ (supplemental Fig. $1 \mathrm{~A}$, available at www.jneurosci.org as supplemental material) shared similar mechanisms to growth cone stalling, i.e., whether it also depended on electrical activity. Thus, we evaluated the rate of outgrowth in control conditions and in cells exposed to $0.5 \mu \mathrm{M}$ kainate for $20 \mathrm{~min}$ in the presence of $1 \mu \mathrm{M}$ TTX. In these conditions, $0.5 \mu \mathrm{M}$ kainate still decreased the average rate of axonal outgrowth, from $0.53 \pm 0.08 \mu \mathrm{m} / \mathrm{min}$ in control conditions to $0.35 \pm 0.04 \mu \mathrm{m} / \mathrm{min}$ in kainate $0.5 \mu \mathrm{M}(n=8 ; p=0.04$, Student's test) (supplemental Fig. $1 C$, available at www.jneurosci.org as supplemental material). Therefore, the decrease in axon outgrowth induced by low concentrations of kainate is mediated by a mechanism different from electrical activity, possibly involving metabotropic signaling pathways.

Because transient bursts of electrical activity constitute a hallmark of the developing brain, we characterized further the role of electrical activity in growth cone stalling. For this purpose, we performed whole-cell recordings of hippocampal neurons in current-clamp configuration, to directly trigger action potential firing by brief current injections, together with simultaneous
Overall, direct electrical stimulation of neurons induces a prominent stalling of growth cones associated with morphological changes involving major cytoskeletal rearrangements (Dent and Gertler, 2003).

We also examined the efficacy of various stimulation protocols for stalling growth cones (Fig. 5C). Decreasing the duration of $10 \mathrm{~Hz}$ stimulation to $10 \mathrm{~s}$ reduced the amplitude of the response but still significantly decreased MI over the whole neuronal population (mean $R=0.91 \pm 0.05 ; n=16$; KS test, $p=0.04$ ). Stimulating neurons at lower frequencies ( $1 \mathrm{~Hz}$ for $40 \mathrm{~s}$ ) slightly decreased MI ratios (mean $R=0.94 \pm 0.03 ; n=18$ ), but this failed to reach statistical significance (KS test, $p=0.08$ ). Finally, we stimulated neurons with the same $1 \mathrm{~Hz}$ overall frequency but grouped in eight bursts of five action potentials at $10 \mathrm{~Hz}$ for a total duration of $40 \mathrm{~s}$. In these conditions, we did not find any significant reduction of motility (mean $R=1.01 \pm 0.04 ; n=16$; KS test, $p=0.8$ ).

The effect of electrical stimulation could be mediated in part by the release of glutamate by the growth cone (Young and Poo, 1983; Gao and van den Pol, 2000), which could in turn activate AMPA and kainate receptors, as shown for axonal filopodia in hippocampal slices (Tashiro et al., 2003). We thus tested the effect of electrical stimulation $(10 \mathrm{~Hz}, 40 \mathrm{~s})$ on growth cone motility in the presence of the AMPA/kainate antagonist NBQX (50 $\mu \mathrm{M})$. In these conditions, electrical stimulation decreased growth cone motility (mean $R=0.79 \pm 0.07 ; n=6$ ) as efficiently as in control medium. Thus, glutamate potentially released by the growth cone does not seem to modulate growth cone motility, by activating 
ionotropic AMPA or kainate receptors in an autocrine manner. Overall, these results indicate that, on the contrary, the effect of kainate is mediated by the triggering of action potentials that directly affect growth cone motility. Therefore, to explore the cellular mechanisms of this effect in detail, we used for the rest of experiments direct electrical stimulation that allows better temporal control and reproducibility than kainate application.

\section{Role of calcium in growth cone stalling by electrical activity}

Intracellular calcium has been widely described as an important regulator of growth cone migration and axonal guidance (Henley and Poo, 2004; Gomez and Zheng, 2006). The arrival of action potentials could mediate a large influx of extracellular $\mathrm{Ca}^{2+}$ at the growth cone through depolarization and subsequent activation of voltage-dependent $\mathrm{Ca}^{2+}$ channels (Augustine et al., 2003). Therefore, we examined the implication of $\left[\mathrm{Ca}^{2+}\right]_{i}$ changes in the fast growth cone stalling induced by electrical stimulation.

First, we evaluated the effect of manipulations of the extracellular as well as intracellular calcium levels over basal growth cone motility in the absence of stimulation (Fig. 6A). The removal of extracellular $\mathrm{Ca}^{2+}$, by perfusing cells for at least 2 min with extracellular medium devoid of $\mathrm{Ca}^{2+}$ and containing $200 \mu \mathrm{M}$ EGTA $\left(0\left[\mathrm{Ca}^{2+}\right]_{\mathrm{e}}\right)$, did not have any apparent effect over growth cone motility (mean MI of $0.27 \pm 0.02, n=8$ in control vs $0.28 \pm 0.02$ in $0\left[\mathrm{Ca}^{2+}\right]_{\mathrm{e}}$; $t$ test, $p=0.79$; $n=8)$. Similarly, incubation with $50 \mu \mathrm{M}$ EGTA-AM for $30 \mathrm{~min}$, which chelates intracellular calcium, did not affect motility (mean MI of $0.26 \pm 0.02 ; p=0.81 ; n=6$ ). However, incubation with $50 \mu \mathrm{M}$ BAPTA-AM for $30 \mathrm{~min}$, another calcium chelator with similar affinity to EGTA$\mathrm{AM}$, but with a higher binding rate (Neher, 1998), dramatically reduced growth cone motility (mean MI of $0.13 \pm 0.02 ; p<0.001 ; n=7)$. These results indicate that fast growth cone motility is dependent on the existence of $\left[\mathrm{Ca}^{2+}\right]_{i}$ microdomains that are resistant to chelation by EGTA-AM.

We next evaluated whether manipulations of intracellular $\mathrm{Ca}^{2+}$ levels affected axonal growth cone stalling mediated by electrical stimulation. Stalling mediated by electrical stimulation was also observed in $0\left[\mathrm{Ca}^{2+}\right]_{\mathrm{e}}$ medium (mean $R=0.90 \pm 0.04$; $n=17$; KS test vs no stimulation, $p=0.03$ ). However, in these conditions, growth cones overall appeared to be less sensitive to electrical stimulation compared with normal $\left[\mathrm{Ca}^{2+}\right]_{\mathrm{e}}$, although the differences between both tested subpopulations did not reach statistical significance (KS test, $p=0.078$ ) (Fig. $6 B$ ). To address in greater detail the role of extracellular $\mathrm{Ca}^{2+}$, we selected cells that did not respond to electrical stimulation in $0\left[\mathrm{Ca}^{2+}\right]_{\mathrm{e}}$ and then performed a second stimulation in normal medium. In 4 of

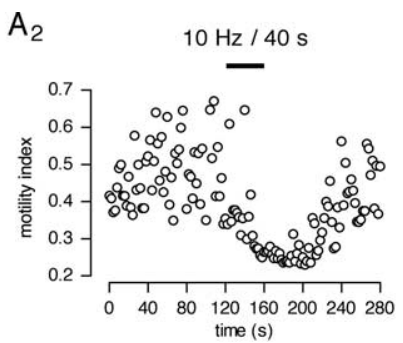

C
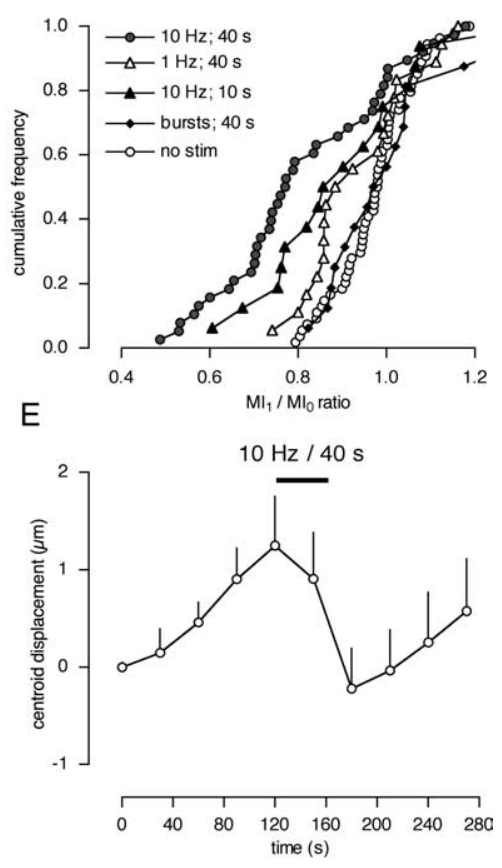

Figure 5. Electrical activity alone suffices to stall growth cones. $\boldsymbol{A}$, Variation of the index of motility for an axonal growth cone of a neuron stimulated at $10 \mathrm{~Hz}$ for $40 \mathrm{~s}$. See supplemental movie 3 (available at www.jneurosci.org as supplemental material). $\boldsymbol{A}_{\boldsymbol{1}}$, Left, Several action potentials (top trace) recorded in a neuron during imaging. Bottom trace, The $10 \mathrm{~ms}$ current injections (500 es during stimulation. Note also the increased filopodia extension after stimulation (shape index in the example raised by , $A_{2}$, Ml graph of the axonal growth cone of the stimulated neuron in $A_{1}$. B, Motility chart showing the mean \pm SEM Ml of 12 motility. The relative potency of the tonic stimulation protocols at constant frequency was as follows: $10 \mathrm{~Hz}, 40 \mathrm{~s}$ (gray circles; $n=$ 38) $>10 \mathrm{~Hz}, 10 \mathrm{~s}$ (black triangles; $n=16)>1 \mathrm{~Hz}, 40 \mathrm{~s}$ (white triangles; $n=18$ ). Finally, a burst stimulation protocol at a global frequency of $1 \mathrm{~Hz}$ ( 5 spikes at $10 \mathrm{~Hz}$, with interstimulus intervals of $4.5 \mathrm{~s}$; black diamonds; $n=16$ ) did not affect growth cone motility. $\boldsymbol{D}$, Chart showing the mean \pm SEM SI of the same growth cones as in $\boldsymbol{B}$. $\boldsymbol{E}$, Graph showing the mean \pm SEM centroid displacement every $30 \mathrm{~s}$ for the same growth cones as in $\boldsymbol{B}$ and $\boldsymbol{D}$. Stimulation induced a reversible retraction of growth cones.

10 such cells, a clear stalling response was observed in normal medium (mean $R=0.93 \pm 0.04$ in $0\left[\mathrm{Ca}^{2+}\right]_{\mathrm{e}}$ vs $0.60 \pm 0.04$ in HBS; $p<0.001$, Student's $t$ test). Thus, at least in some neurons, $\mathrm{Ca}^{2+}$ entry from the extracellular medium is necessary and sufficient for electrical stimulation to affect growth cone motility, whereas in other neurons, it is not. To address the role of intracellular $\mathrm{Ca}^{2+}$ further, we stimulated neurons previously loaded with EGTA-AM. Stalling was still induced (mean $R=0.86 \pm$ $0.03 ; n=18$. KS test vs no stimulation, $p=0.006$ ) (Fig. $6 B$ ). This suggests that calcium microdomains resistant to chelation by intracellular EGTA are involved in both the basal motility of growth cones and its regulation by electrical activity.

Because we found that manipulating $\left[\mathrm{Ca}^{2+}\right]_{\mathrm{i}}$ could affect growth cone stalling, we examined in more detail the spatiotemporal pattern of $\left[\mathrm{Ca}^{2+}\right]_{\mathrm{i}}$ changes at the growth cone during stimulation. We transfected hippocampal neurons with DsRed to im- 
A

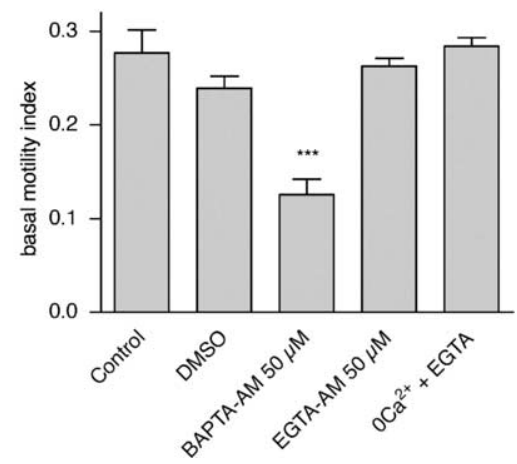

B

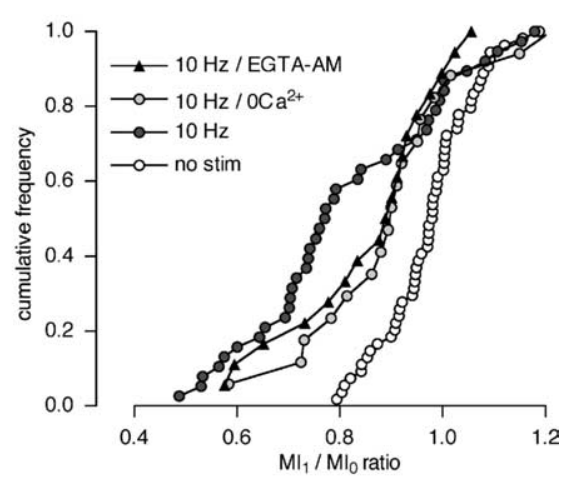

Figure 6. Regulation of fast growth cone motility and growth cone stalling by calcium. $\boldsymbol{A}$, The cell-permeable $\mathrm{Ca}^{2+}$ chelator BAPTA-AM drastically diminishes basal growth cone motility $\left({ }^{* * *} p<0.001\right.$, Tukey's test, ANOVA), whereas its analog EGTA-AM, or the removal of extracellular $\mathrm{Ca}^{2+}$ did not influence it. $\boldsymbol{B}$, Effect of $0\left[\mathrm{Ca}^{2+}\right]_{\mathrm{e}}$ (light gray circles) and EGTA-AM (black triangles) on the rate of stalling response of growth cones from neurons stimulated at $10 \mathrm{~Hz}$ for $40 \mathrm{~s}$.

age growth cone motility and loaded them with the calcium indicator Fluo-4-AM to simultaneously monitor $\left[\mathrm{Ca}^{2+}\right]_{\mathrm{i}}$. When neurons fired action potentials at $10 \mathrm{~Hz}$, Fluo- 4 fluorescence rose rapidly throughout the entire growth cone (Fig. $7 A-C$ ) (supplemental movie 4, available at www.jneurosci.org as supplemental material) to a plateau level ( $139 \pm 40 \% \Delta F / F ; n=16)$ that persisted during the whole stimulation period and returned rapidly to basal levels after the stimulation had ceased. When imaged at higher temporal resolution $(20 \mathrm{~Hz}$ frame acquisition instead of $0.5 \mathrm{~Hz}$ ) (Fig. 7D), Fluo-4 fluorescence rose after the first action potential and reached a plateau after approximately eight action potentials, or $800 \mathrm{~ms}$. However, there was no correlation between Fluo-4 increase in fluorescence and growth cone motility imaged in parallel by DsRed (Pearson's $\left.r^{2}=0.05\right)$ (Fig. $7 E$ ). Indeed, in stalling $(n=7)$ (Fig. $7 B)$ and nonstalling $(n=9)$ (Fig. 7C) growth cones, the bulk intracellular calcium concentration reached similar levels with similar kinetics. To rule out potential artifacts attributable to saturation of the indicator, we used Fluo-5F-AM, another $\mathrm{Ca}^{2+}$-sensitive probe with lower affinity $\left(K_{\mathrm{d}}\right.$ of $\left.2.3 \mu \mathrm{M}\right)$ than Fluo-4-AM ( $K_{\mathrm{d}}$ of $\left.345 \mathrm{nM}\right)$. In stimulated neurons, we found that the evoked $\left[\mathrm{Ca}^{2+}\right]_{\mathrm{i}}$ signal at the growth cone assessed by Fluo-5F was on average lower in magnitude, but the kinetics and profile of the signal were essentially the same as that obtained with Fluo-4 (supplemental Fig. 2, available at www.jneurosci.org as supplemental material). Moreover, we found again a lack of correlation between the amplitude of the $\mathrm{Ca}^{2+}$ signal and the growth cone motility change (supplemental Fig. $2 C$, available at www.jneurosci.org as supplemental material). Responding (supplemental Fig. $2 A$, available at www.jneurosci.org as supplemental material) and nonresponding (supplemental Fig. $2 B$, available at www.jneurosci.org as supplemental material) neurons presented comparable increases in Fluo-5F fluorescence. Thus, the different sensitivity to growth cone stalling is not attributable to differences in the stimulation-evoked bulk $\left[\mathrm{Ca}^{2+}\right]_{\mathrm{i}}$ increase, as detected by any of these two indicators.

\section{Calcium from intracellular stores contributes to stimulation- induced growth cone stalling}

Extracellular $\mathrm{Ca}^{2+}$ entry does not represent the only way for increasing $\left[\mathrm{Ca}^{2+}\right]_{\mathrm{i}}$ within axonal growth cones after electrical stimulation. Alternative sources could contribute to shape and/or amplify the $\left[\mathrm{Ca}^{2+}\right]_{\mathrm{i}}$ signal, such as release from $\mathrm{Ca}^{2+}$ containing intracellular stores. However, when extracellular

$\mathrm{Ca}^{2+}$ was removed $\left(0\left[\mathrm{Ca}^{2+}\right]_{\mathrm{e}}\right)$, we could not detect any significant Fluo-4 fluorescence increase, even at high frequency imaging (Fig. $7 D$ ), globally, or locally in parts of the growth cone, or when the stimulation was continued for $40 \mathrm{~s}$ (Fig. $7 E$ ). As the results with EGTA-AM incubated cells suggest, there could still occur local $\left[\mathrm{Ca}^{2+}\right]_{\mathrm{i}}$ increases from intracellular stores that would remain undetected in our recording conditions, i.e., microdomains (Neher, 1998), which could mediate the stalling effects observed.

The endoplasmic reticulum (ER) is a strong candidate to mediate intracellular $\mathrm{Ca}^{2+}$ release. The presence of $\mathrm{ER} \mathrm{Ca}^{2+}$ stores has been demonstrated in growth cones from hippocampal neurons in culture (Bouchard et al., 2003). Moreover, ryanodine and caffeine-sensitive $\mathrm{Ca}^{2+}$ pools are known to regulate $\left[\mathrm{Ca}^{2+}\right]_{\mathrm{i}}$ in growth cones (Lipscombe et al., 1988; Barish, 1991). To evaluate the contribution of the $\mathrm{ER} \mathrm{Ca}^{2+}$ stores over axonal growth cone stalling, we designed a protocol for depleting $\mathrm{Ca}^{2+}$ in the ER before electrical stimulation, by the combined use of caffeine $(10 \mathrm{mM})$ and $0\left[\mathrm{Ca}^{2+}\right]_{\mathrm{e}}$ medium, in cells preincubated with ryanodine $(1 \mu \mathrm{M})$ or thapsigargin $(0.5 \mu \mathrm{M})$, which deplete $\mathrm{Ca}^{2+}$ stores in a few minutes. These manipulations minimally affected basal motility (mean MI of $0.26 \pm 0.02, n=$ 14 and $0.22 \pm 0.02, n=9$ for ryanodine and thapsigargin protocols, respectively). However, in these conditions, electrical stimulation no longer affected growth cone motility (mean $R=$ $0.96 \pm 0.03$ in ryanodine and mean $R=1.00 \pm 0.02 \%$ in thapsigargin; all $R$ values $>0.79$ ) (Fig. $7 F$ ). As expected, stimulation in these conditions did not induce any Fluo- 4 fluorescence increase (data not shown). Therefore, axonal growth cone stalling mediated by action potentials is dependent on $\left[\mathrm{Ca}^{2+}\right]_{\mathrm{i}}$ rises that can be mediated by $\mathrm{Ca}^{2+}$ entry through plasma membrane channels as well as by $\mathrm{Ca}^{2+}$ release from ER $\mathrm{Ca}^{2+}$ stores, and the contribution of both could vary among different cells.

We further characterized the pathway of $\mathrm{Ca}^{2+}$ release from the ER that affects growth cone motility. In this regard, $\mathrm{Ca}^{2+}$ could be released from ryanodine receptors (RyR) or from $\mathrm{IP}_{3}$ receptors, so we decided to interfere with each release pathway separately. RyR are classically involved in $\mathrm{Ca}^{2+}$-induced $\mathrm{Ca}^{2+}$ release processes (Verkhratsky, 2005). To selectively block $\mathrm{Ca}^{2+}$ release from RyR, we incubated cells with ryanodine at high concentration $(50 \mu \mathrm{M})$. Basal motility was minimally affected by 50 $\mu \mathrm{M}$ ryanodine (mean MI of $0.21 \pm 0.02$ ). This treatment alone did not decrease the extent of growth cone stalling induced by electrical stimulation (mean $R=0.74 \pm 0.05$; two-thirds of cones presented $R<0.79 ; n=9$ ). In fact, the rate of response was somewhat increased, although not significantly ( $p=0.21$, KS test with respect to stimulation in control conditions) (Fig. 7E). The remaining $\mathrm{Ca}^{2+}$ release pathway from the ER involves $\mathrm{IP}_{3-}$ sensitive receptors. Interestingly, it has been shown recently in cerebellar granule neurons that depolarization alone can activate phospholipase $C$ (PLC) via $G_{\mathrm{q}}$-proteins, leading to phosphatidylinositol-4,5-biphosphate hydrolysis and $\mathrm{IP}_{3}$ production in a mechanism completely independent of $\mathrm{Ca}^{2+}$ influx (Billups et al., 2006). To block $\mathrm{IP}_{3}$-mediated $\mathrm{Ca}^{2+}$ release, we used the widely used $\mathrm{IP}_{3}$ channel blocker 2-APB. Interestingly, when neurons were incubated for $15 \mathrm{~min}$ in the presence of $100 \mu \mathrm{M} 2-\mathrm{APB}$, this dramatically blocked basal growth cone motility (mean MI of 


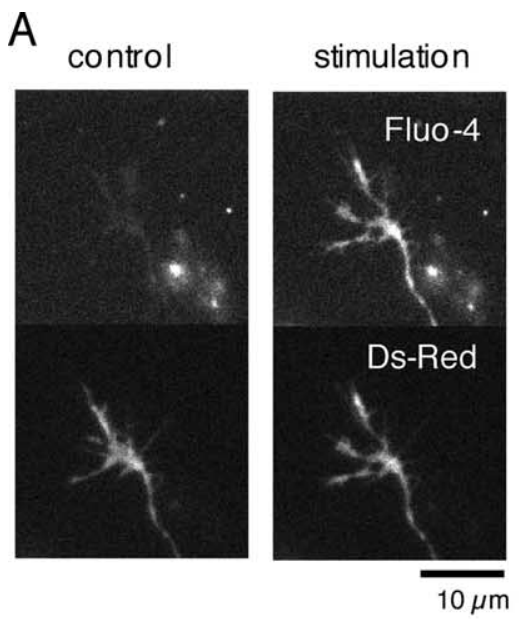

D

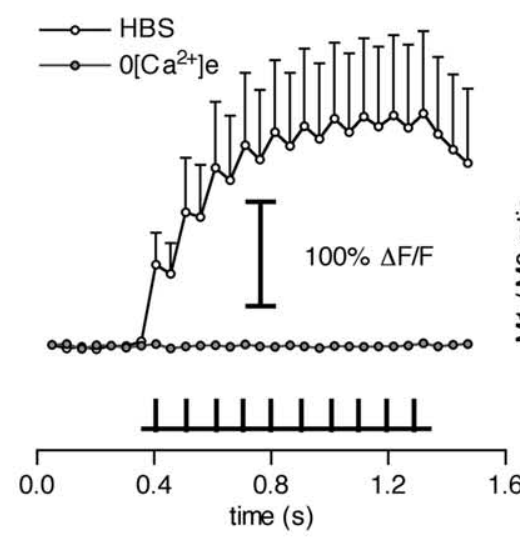

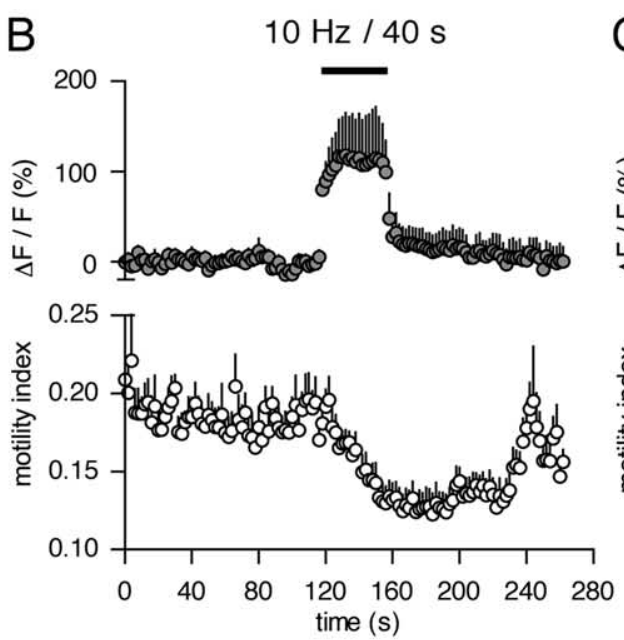
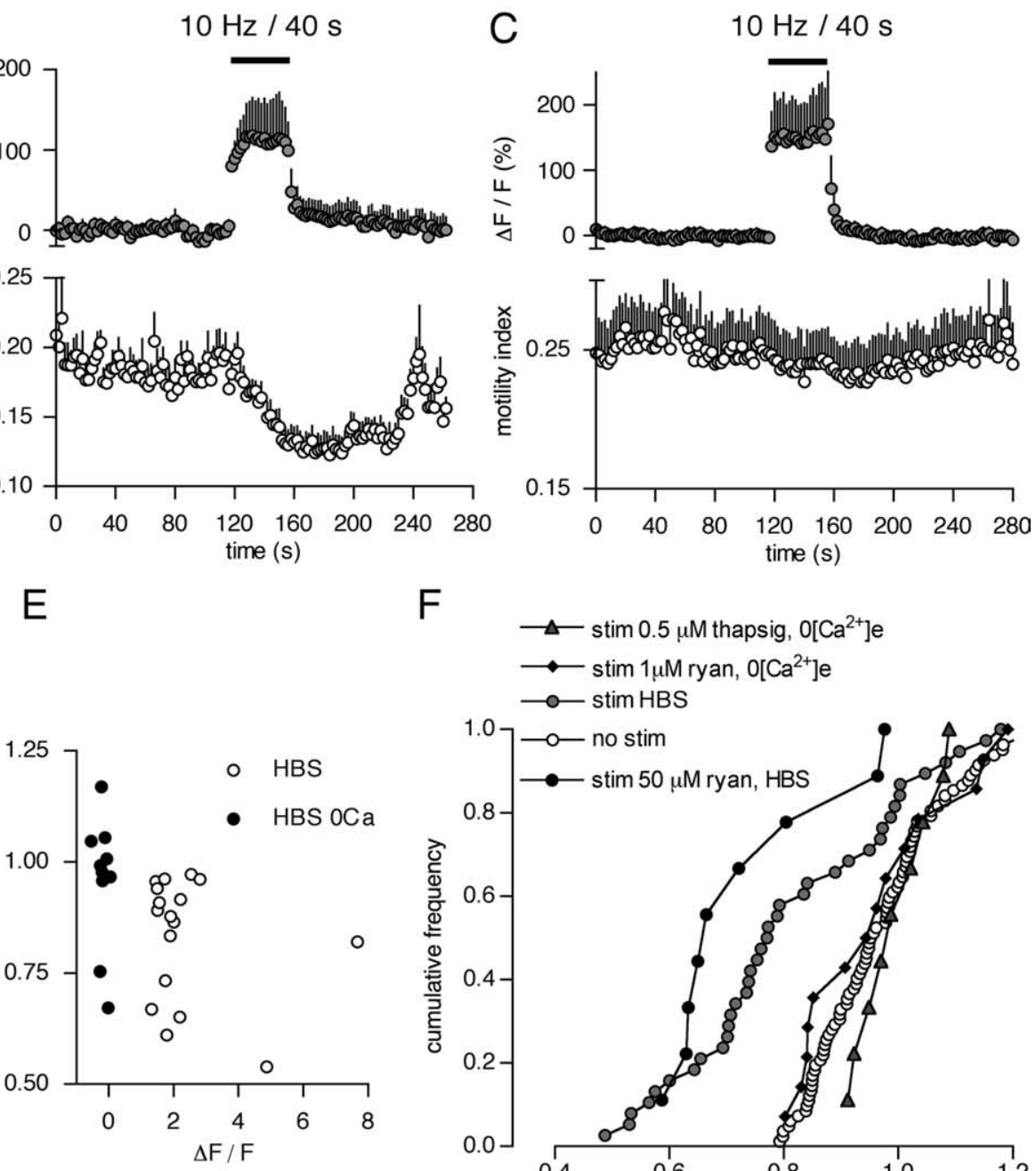

Figure 7. Dynamics of $\left[\mathrm{Ca}^{2+}\right]_{i}$ at the growth cone and contribution of calcium stores to stalling. $A$, Dual Fluo-4/DsRed imaging of a growth cone, presenting a widespread Fluo-4 increase when stimulated at $10 \mathrm{~Hz}$. See also supplemental movie 4 (available at www.jneurosci.org as supplemental material). Both stalling $(n=7 ; \boldsymbol{B})$ and nonstalling $(n=9 ; \boldsymbol{C}$ growth cones present increases in $\left[\mathrm{Ca}^{2+}\right]_{\mathrm{i}}$ when stimulated at $10 \mathrm{~Hz}$ for $40 \mathrm{~s}$, as assessed by Fluo-4 fluorescence. $D$, Fluo-4 increases induced by electrical stimulation (bottom trace) occur rapidly and are completely abolished in $0[\mathrm{Ca}]_{\mathrm{e}}$ medium $(n=10)$. $\boldsymbol{E}$, Lack of correlation between the stalling response $R$ and the magnitude of Fluo-4 fluorescence increases $(\Delta F / F)$, in the presence $(n=16)$ and absence $(n=10)$ of extracellular $\mathrm{Ca}^{2+} . \boldsymbol{F}$, Stimulation at $10 \mathrm{~Hz}$ for 40 s fails to induce growth cone stalling in $0\left[\mathrm{Ca}^{2+}\right]_{\mathrm{e}}$ conditions when the ER stores have been depleted previously of $\mathrm{Ca}{ }^{2+}$, by preincubation with 1 $\mu \mathrm{m}$ ryanodine (black diamonds; $n=14$ ) or $0.5 \mu \mathrm{m}$ thapsigargin (gray triangles; $n=9$ ) and subsequent exposure to $10 \mathrm{~mm}$ caffeine for $30 \mathrm{~s}$ in $0\left[\mathrm{Ca}^{2+}\right]_{\mathrm{e}}$. However, direct block of RyR by $50 \mu \mathrm{m}$ ryanodine does not diminish the stalling response of $10 \mathrm{~Hz}$ stimulation (black circles; $n=9$ ).

$0.11 \pm 0.01 ; p<0.01$, Student's test; $n=10$ ). However, 2 -APB is a nonspecific blocker of $\mathrm{IP}_{3}$ receptors (Peppiatt et al., 2003). We thus interfered selectively with the $\mathrm{IP}_{3}$ pathway upstream, incubating cells with the specific PLC inhibitor U73122 (1[6[ [(17 $\beta$ )-3-methoxyestra-1,3,5(10)-trien-17-yl] amino] hexyl]-1 $H$-pyrrole-2,5-dione) (1 $\mu \mathrm{M} ; 15 \mathrm{~min})$. We found that, like 2-APB, U73122 dramatically and irreversibly blocked basal growth cone motility (mean MI of $0.08 \pm 0.01$; $p<0.01$, Student's test; $n=5)$. Importantly, this effect was not observed with its structural analog U73343 (1-[6-((17 $\beta$ 3-methoxyestra-1,3,5(10)-trien-17-yl)amino)hexyl]-2,5pyrrolidine-dione) (mean MI of $0.24 \pm 0.03$ ). Despite a dramatic action over growth cones, cells recorded in the presence of U73122 presented normal electrophysiological parameters (data not shown). In conclusion, because of its dramatic effect over basal MI, we could not assess the response to stimulation in conditions of PLC- $\mathrm{IP}_{3}$ blockade, but this result indicates that $\mathrm{PLC}-\mathrm{IP}_{3}$ pathway activity tonically modulates basal growth cone motility. Receptor classes that activate the PLC pathway through $\mathrm{G}_{\mathrm{q}}$-proteins include, among others, $\alpha 1$ adrenergic, muscarinic, and group I metabotropic glutamate receptors (mGluRs). Given that electrical activity could induce the release of glutamate at the growth cone, we tested whether the latter subtype of receptors were involved in the stalling of growth cones by action potentials. Incubation of neurons for $30 \mathrm{~min}$ in the presence of $50 \mu \mathrm{M}$ LY341495 [(2S)2-amino-2-[(1S,2S)-2-carboxycycloprop-1-yl]-3-(xanth-9yl) propanoic acid], which at this concentration blocks all mGluRs (Fitzjohn et al., 1998), did not affect basal motility (MI of $0.30 \pm 0.01 ; n=16$ ). Thus, normal growth cone motility in our system is not maintained by a tonic activation of mGluRs. When we tested the effect of $50 \mu \mathrm{M}$ LY341495 over the response to stimulation, we found that the rate of stalling (mean $R=0.84 \pm 0.07 ; n=16$ ) was not significantly diminished with respect to stimulation in control conditions (KS test, $p=0.14)$. 


\section{Discussion}

\section{Electrical activity regulates axonal growth cone motility}

It has long been known that long-term electrical stimulation of neurons (several minutes to days) inhibits axon outgrowth (Cohan and Kater, 1986; Fields et al., 1990; Diefenbach et al., 2000). However, contrary to the long stimulation periods tested so far, the patterns of electrical activity observed in vivo are often structured in bursts only lasting seconds to $1 \mathrm{~min}$ at most (O'Donovan, 1999; Ben-Ari, 2001). Here, we characterized the effects of short episodes of electrical activity on axonal growth cones. We have shown that transient neuronal activity, i.e., action potentials at $10 \mathrm{~Hz}$ for $10 \mathrm{~s}$, rapidly and reversibly affects the motility of axonal growth cones in cultured hippocampal neurons.

It has been proposed that the activation of excitatory glutamate receptors could locally affect the behavior of axonal filopodia (Chang and De Camilli, 2001; Schenk et al., 2003; Tashiro et al., 2003). In our recording conditions, we show that the activation of GluR6-containing kainate receptors by bath application of kainate reversibly stalls growth cones. However, this effect only took place when action potentials were recorded at the somatic level during kainate application, and it was completely blocked by TTX. In addition, the effect of kainate receptor activation on growth cone motility was mimicked by intracellular current injections. This argues in favor of a mechanism in which the primary effect of kainate receptors is to trigger action potential discharge that in turn affects growth cone motility. However, low concentrations of kainate $(0.5 \mu \mathrm{M})$, which do not affect rapid growth cone motility, can decrease the rate of axonal outgrowth by a mechanism that, contrary to stalling, is not blocked by TTX and might involve metabotropic signaling cascades (Lerma, 2003; Pinheiro and Mulle, 2006).

In hippocampal cultured slices, the changes in motility of dentate granule cell axonal filopodia induced by exogenous kainate were mimicked by electrical stimulation at high frequency $(25 \mathrm{~Hz}$ for $15 \mathrm{~min}$ ), and these effects were blocked by CNQX (but not by GYKI53655), suggesting that they were attributable to the activation of kainate receptors by glutamate released by the growth cone itself (Tashiro et al., 2003). In our experimental conditions, blocking ionotropic or metabotropic glutamate receptors did not affect the response to electrical stimulation. Thus, in our model, glutamate potentially released by the growth cone does not modulate growth cone motility. However, cultured neurons are isolated, and it is conceivable that, in the denser environment of the brain tissue, higher glutamate concentrations would be reached locally after episodes of electrical activity in vivo. In any case, besides indirect mechanisms involving neurotransmitter secretion, our results suggest that specific patterns of electrical activity directly contribute to regulate the dynamic behavior of growth cones in the developing brain.

\section{Mechanisms of growth cone stalling by electrical activity}

The effect of electrical activity on growth cone motility was calcium dependent, because it was partially inhibited by incubating the cells in $0[\mathrm{Ca}]_{\mathrm{e}}$ medium or EGTA-AM. However, neither treatment completely abolished the effect, despite a near complete block of bulk cytosolic calcium concentration increase during stimulation, as measured with Fluo-4 and Fluo-5F. Moreover, there was no correlation between intracellular calcium increase at the growth cone, as measured by any of these two indicators, and decreased motility. To completely block the effect of electrical stimulation, we had to use $0[\mathrm{Ca}]_{\mathrm{e}}$ medium together with treatments that deplete ER calcium stores. Therefore, we propose that axonal growth cone stalling requires both extracellular calcium and intracellular stores that will act locally, in microdomains that are too small to be imaged by conventional techniques and that are resistant to buffering by EGTA. Other $\mathrm{Ca}^{2+}$ microdomain-regulated processes have been extensively described in neurons, such as neurotransmitter release in presynaptic terminals (Augustine et al., 2003) and growth cone steering and migration (Henley and Poo, 2004; Gomez and Zheng, 2006).

What is the nature of the ER store that mediates part of the stalling effect in $0[\mathrm{Ca}]_{\mathrm{e}}$ conditions? The hypothesis that best fits with our experimental data is that it contains a mixed population of RyR and $\mathrm{IP}_{3}$ receptors. Depletion of RyR-containing stores by $1 \mu \mathrm{M}$ ryanodine abolishes the stalling response, but directly blocking $\mathrm{RyR} \mathrm{Ca}^{2+}$ release by $50 \mu \mathrm{M}$ ryanodine does not markedly affect it. This could be explained by the action of $\mathrm{IP}_{3}$ receptor channels. Accordingly, we found that the chronic blockade of the $\mathrm{PLC}-\mathrm{IP}_{3}$ signaling pathway by incubation with both the $\mathrm{IP}_{3}$ receptor blocker 2-APB and the PLC inhibitor U73122 (but not its analog U73343) exerts by itself a dramatic effect over growth cone motility.

It should be noted nonetheless that the stalling effect by electrical activity was not observed in all growth cones and that, in some cases, only extracellular calcium was required. This could simply be attributable to differences in neuronal populations that are quite heterogeneous in the hippocampus. Alternatively, this could be attributable to the internal state of the growth cone, governed in particular by intracellular concentrations of cAMP and cGMP, which can regulate ER $\mathrm{Ca}^{2+}$ release (Gomez and Zheng, 2006). In particular, dorsal root ganglion neurons growing on different substrates show a different involvement of RyR in growth cone guidance, depending on cAMP levels and RyR phosphorylation by protein kinase A (Ooashi et al., 2005).

The decrease in growth cone motility reached a maximum at the end of the $40 \mathrm{~s}$ stimulation, whereas $[\mathrm{Ca}]_{\mathrm{i}}$ increases reached a plateau level in $<1 \mathrm{~s}$. This leaves ample time for a number of calcium-activated cellular processes that affect actin cytoskeleton dynamics (Henley and Poo, 2004). For instance, the calciumactivated protease calpain is activated locally to affect growth cone filopodia (Robles et al., 2003). Moreover, several other actin binding proteins could potentially mediate growth cone stalling (Dent and Gertler, 2003). Among these, the actin depolymerizing factor and cofilin are implicated in the regulation of neurite outgrowth and filopodia dynamics (Meberg and Bamburg, 2000; Gehler et al., 2004). Other candidates include the calciumdependent protein gelsolin (Lu et al., 1997) and the brain-specific protein profilin $2 \mathrm{~A}$, which is targeted to dendritic spines by neuronal activity (Ackermann and Matus, 2003). Importantly, all of these proteins are recruited to the plasma membrane by binding to PtdIns(4,5)P2, the substrate of PLC, and membrane PtdIns(4,5)P2 levels are known to play a critical role in the control of actin dynamics and cell migration (Ling et al., 2006).

\section{Electrical activity and the formation of neuronal connectivity} In this study, we report that transient electrical activity rapidly decreases neuronal growth cone motility. Longer stimulations eventually lead to growth cone collapse (Diefenbach et al., 2000). In addition, electrical activity could control the integration by growth cones of signals arising from local cues. For instance, a light electrical stimulation of Xenopus motoneurons (10 action potentials at $2 \mathrm{~Hz}$ ), which does not by itself induce any change in axonal outgrowth, is able to lower the sensitivity of growth cones to attractive guidance cues or convert repulsive cues into attractive ones (Ming et al., 2001). This effect could depend on in- 
creased filopodia extension (Zheng et al., 1996). Interestingly, we found that electrical stimulation increases the shape irregularity of growth cones, which reflects an increased filopodial extension. This could lead to a differential sensitivity to guidance cues. More generally, the regulation of axonal guidance and growth cone stabilization could provide a mechanism for the fine control of network formation by coordinated neuronal activity of presynaptic elements and their eventual targets (Goodman and Shatz, 1993; Zhang and Poo, 2001).

The decrease of filopodial motility was proposed to favor synaptogenesis by facilitating the formation of early adhesive contacts between the axonal growth cone and the postsynaptic target (Tashiro et al., 2003). However, it should be noted that, instead, when activity is blocked by TTX, the number of aberrant contacts between growing axons and target cortical areas is increased both in cortical slices (Dantzker and Callaway, 1998) and in vivo (Catalano and Shatz, 1998). In general, blocking neuronal activity compromises the ability to make accurate synaptic contacts, but this does not impair the process of synaptogenesis itself (Goodman and Shatz, 1993; Lauri et al., 2003). Therefore, stabilizing growth cone motility and extension could actually prevent excessive axon outgrowth and the formation of aberrant synaptic contacts.

Because spontaneous electrical activity plays a role in the generation of precise patterns of connectivity, this leads to the question of what is the source of that activity during development. Interestingly, the tonic release of GABA and glutamate, as well as depolarizing currents induced by these agents can be detected at very early developmental stages in the hippocampus, before the formation of synaptic connections (Demarque et al., 2002). Thus, before the formation of synapses, early forms of electrical communication between neurons exist, which involve neurotransmitter release by growth cones (Young and Poo, 1983) or glial cells (Bezzi et al., 2004). In this regard, the activation of kainate receptors by ambient glutamate could have a crucial role to control the excitability of different neuronal populations early in development (Lauri et al., 2005) as well as the motility of axonal growth cones before synapse formation.

\section{References}

Ackermann M, Matus A (2003) Activity-induced targeting of profilin and stabilization of dendritic spine morphology. Nat Neurosci 6:1194-1200.

Augustine GJ, Santamaria F, Tanaka K (2003) Local calcium signaling in neurons. Neuron 40:331-346.

Barish ME (1991) Increases in intracellular calcium ion concentration during depolarization of cultured embryonic Xenopus spinal neurones. J Physiol (Lond) 444:545-565.

Ben-Ari Y (2001) Developing networks play a similar melody. Trends Neurosci 24:353-360.

Bezzi P, Gundersen V, Galbete JL, Seifert G, Steinhauser C, Pilati E, Volterra A (2004) Astrocytes contain a vesicular compartment that is competent for regulated exocytosis of glutamate. Nat Neurosci 7:613-620.

Billups D, Billups B, Challiss RA, Nahorski SR (2006) Modulation of $\mathrm{G}_{\mathrm{q}^{-}}$ protein-coupled inositol trisphosphate and $\mathrm{Ca}^{2+}$ signaling by the membrane potential. J Neurosci 26:9983-9995.

Bouchard R, Pattarini R, Geiger JD (2003) Presence and functional significance of presynaptic ryanodine receptors. Prog Neurobiol 69:391-418.

Catalano SM, Shatz CJ (1998) Activity-dependent cortical target selection by thalamic axons. Science 281:559-562.

Chang S, De Camilli P (2001) Glutamate regulates actin-based motility in axonal filopodia. Nat Neurosci 4:787-793.

Cohan CS, Kater SB (1986) Suppression of neurite elongation and growth cone motility by electrical activity. Science 232:1638-1640.

Coussen F, Perrais D, Jaskolski F, Sachidhanandam S, Normand E, Bockaert J, Marin P, Mulle C (2005) Co-assembly of two GluR6 kainate receptor splice variants within a functional protein complex. Neuron 47:555-566.
Dantzker JL, Callaway EM (1998) The development of local, layer-specific visual cortical axons in the absence of extrinsic influences and intrinsic activity. J Neurosci 18:4145-4154.

Demarque M, Represa A, Becq H, Khalilov I, Ben-Ari Y, Aniksztejn L (2002) Paracrine intercellular communication by a $\mathrm{Ca}^{2+}$ - and SNARE- independent release of GABA and glutamate prior to synapse formation. Neuron 36:1051-1061.

Dent EW, Gertler FB (2003) Cytoskeletal dynamics and transport in growth cone motility and axon guidance. Neuron 40:209-227.

Diefenbach TJ, Guthrie PB, Kater SB (2000) Stimulus history alters behavioral responses of neuronal growth cones. J Neurosci 20:1484-1494.

Fields RD, Neale EA, Nelson PG (1990) Effects of patterned electrical activity on neurite outgrowth from mouse sensory neurons. J Neurosci 10:2950-2964.

Fischer M, Kaech S, Wagner U, Brinkhaus H, Matus A (2000) Glutamate receptors regulate actin-based plasticity in dendritic spines. Nat Neurosci 3:887-894.

Fitzjohn SM, Bortolotto ZA, Palmer MJ, Doherty AJ, Ornstein PL, Schoepp DD, Kingston AE, Lodge D, Collingridge GL (1998) The potent mGlu receptor antagonist LY341495 identifies roles for both cloned and novel mGlu receptors in hippocampal synaptic plasticity. Neuropharmacology 37:1445-1458.

Gallo G, Letourneau PC (2004) Regulation of growth cone actin filaments by guidance cues. J Neurobiol 58:92-102.

Gao XB, van den Pol AN (2000) GABA release from mouse axonal growth cones. J Physiol (Lond) 523:629-637.

Gehler S, Shaw AE, Sarmiere PD, Bamburg JR, Letourneau PC (2004) Brain-derived neurotrophic factor regulation of retinal growth cone filopodial dynamics is mediated through actin depolymerizing factor/ cofilin. J Neurosci 24:10741-10749.

Gomez TM, Zheng JQ (2006) The molecular basis for calcium-dependent axon pathfinding. Nat Rev Neurosci 7:115-125.

Goodman CS, Shatz CJ (1993) Developmental mechanisms that generate precise patterns of neuronal connectivity. Cell [Suppl] 72:77-98.

Henley J, Poo MM (2004) Guiding neuronal growth cones using $\mathrm{Ca}^{2+}$ signals. Trends Cell Biol 14:320-330.

Huber AB, Kolodkin AL, Ginty DD, Cloutier JF (2003) Signaling at the growth cone: ligand-receptor complexes and the control of axon growth and guidance. Annu Rev Neurosci 26:509-563.

Jaskolski F, Coussen F, Nagarajan N, Normand E, Rosenmund C, Mulle C (2004) Subunit composition and alternative splicing regulate membrane delivery of kainate receptors. J Neurosci 24:2506-2515.

Jaskolski F, Coussen F, Mulle C (2005) Subcellular localization and trafficking of kainate receptors. Trends Pharmacol Sci 26:20-26.

Kalil K, Dent EW (2005) Touch and go: guidance cues signal to the growth cone cytoskeleton. Curr Opin Neurobiol 15:521-526.

Lauri SE, Lamsa K, Pavlov I, Riekki R, Johnson BE, Molnar E, Rauvala H, Taira T (2003) Activity blockade increases the number of functional synapses in the hippocampus of newborn rats. Mol Cell Neurosci 22:107-117.

Lauri SE, Segerstrale M, Vesikansa A, Maingret F, Mulle C, Collingridge GL, Isaac JT, Taira T (2005) Endogenous activation of kainate receptors regulates glutamate release and network activity in the developing hippocampus. J Neurosci 25:4473-4484.

Lerma J (2003) Roles and rules of kainate receptors in synaptic transmission. Nat Rev Neurosci 4:481-495.

Ling K, Schill NJ, Wagoner MP, Sun Y, Anderson RA (2006) Movin' on up: the role of PtdIns $(4,5) \mathrm{P}(2)$ in cell migration. Trends Cell Biol 16:276-284.

Lipscombe D, Madison DV, Poenie M, Reuter H, Tsien RW, Tsien RY (1988) Imaging of cytosolic $\mathrm{Ca}^{2+}$ transients arising from $\mathrm{Ca}^{2+}$ stores and $\mathrm{Ca}^{2+}$ channels in sympathetic neurons. Neuron 1:355-365.

Lu M, Witke W, Kwiatkowski DJ, Kosik KS (1997) Delayed retraction of filopodia in gelsolin null mice. J Cell Biol 138:1279-1287.

Meberg PJ, Bamburg JR (2000) Increase in neurite outgrowth mediated by overexpression of actin depolymerizing factor. J Neurosci 20:2459-2469.

Ming G, Henley J, Tessier-Lavigne M, Song H, Poo M (2001) Electrical activity modulates growth cone guidance by diffusible factors. Neuron 29:441-452.

Neher E (1998) Usefulness and limitations of linear approximations to the understanding of $\mathrm{Ca}^{++}$signals. Cell Calcium 24:345-357.

O’Donovan MJ (1999) The origin of spontaneous activity in developing 
networks of the vertebrate nervous system. Curr Opin Neurobiol 9:94-104.

Ooashi N, Futatsugi A, Yoshihara F, Mikoshiba K, Kamiguchi H (2005) Cell adhesion molecules regulate $\mathrm{Ca}^{2+}$-mediated steering of growth cones via cyclic AMP and ryanodine receptor type 3. J Cell Biol 170:1159-1167.

Peppiatt CM, Collins TJ, Mackenzie L, Conway SJ, Holmes AB, Bootman MD, Berridge MJ, Seo JT, Roderick HL (2003) 2-Aminoethoxydiphenyl borate (2-APB) antagonises inositol 1,4,5-trisphosphate-induced calcium release, inhibits calcium pumps and has a use-dependent and slowly reversible action on store-operated calcium entry channels. Cell Calcium 34:97-108.

Pinheiro P, Mulle C (2006) Kainate receptors. Cell Tissue Res 326:457-482.

Robles E, Huttenlocher A, Gomez TM (2003) Filopodial calcium transients regulate growth cone motility and guidance through local activation of calpain. Neuron 38:597-609.

Schenk U, Verderio C, Benfenati F, Matteoli M (2003) Regulated delivery of
AMPA receptor subunits to the presynaptic membrane. EMBO J 22:558-568.

Tashiro A, Dunaevsky A, Blazeski R, Mason CA, Yuste R (2003) Bidirectional regulation of hippocampal mossy fiber filopodial motility by kainate receptors: a two-step model of synaptogenesis. Neuron 38:773-784.

Verkhratsky A (2005) Physiology and pathophysiology of the calcium store in the endoplasmic reticulum of neurons. Physiol Rev 85:201-279.

Young SH, Poo MM (1983) Spontaneous release of transmitter from growth cones of embryonic neurones. Nature 305:634-637.

Zhang LI, Poo MM (2001) Electrical activity and development of neural circuits. Nat Neurosci [Suppl] 4:1207-1214.

Zheng JQ, Felder M, Connor JA, Poo MM (1994) Turning of nerve growth cones induced by neurotransmitters. Nature 368:140-144.

Zheng JQ, Wan JJ, Poo MM (1996) Essential role of filopodia in chemotropic turning of nerve growth cone induced by a glutamate gradient. J Neurosci 16:1140-1149. 